\title{
REVIEW OF DESIGN RESEARCH FOR SUSTAINABLE DEVELOPMENT IN AFRICA: A DESIGN SCIENCE PERSPECTIVE
}

\author{
T. W. Barlow ${ }^{\bowtie}$, M. T. Greene and P. Y. Papalambros \\ University of Michigan, United States of America \\ $\bigotimes$ twbarlow@umich.edu
}

\begin{abstract}
The design community can contribute significantly to the success of the United Nations Sustainable Development Goals in Africa. Currently, alignment of the design research community on sustainable development goals in Africa is not well understood. In this paper, we review relevant literature and identify trends in research topics studied and in patterns of collaboration between researchers. We find differences in topic representation and collaboration trends between African-based and non-African based researchers. Understanding these differences better will be important for future research.
\end{abstract}

Keywords: design research, sustainable design, sustainable development, design knowledge, design science

\section{Introduction}

The UN Sustainable Development Goals (SDGs) are a call to action to improve the world over the next 10 years. The worldwide design community must be an integral part of the SDGs success and design thinking is a valuable approach for developing solutions that meet the SGDs. Arguably, Africa as a continent presents a key challenge and opportunity for pursuing the SDGs with current progress there towards the SDG targets deemed insufficient for achieving the goals by 2030 (United Nations, 2019). For the goals to be realized, the design communities from within and outside Africa must be connected, aligned, and practice design thinking. The success of the UN initiative depends on this collective effort. This paper is an effort to map out the relevant design research efforts in Africa based on the extant published scientific literature.

Currently, design and engineering research in Africa is inadequate despite increased research growth (Patra and Muchie, 2017). As stated by Djeflat (2017), the design capabilities in Africa are lacking and contribute to unachieved development potential in the region. Collaboration and capacity building with the international design community is important for creating sustainable solutions in Africa. Some organizations such as the Design Society (2019) have initiatives to drive the creation of a network of designers interested in applying design thinking in Africa. Other design groups have made strides towards applying design methodology and design thinking to the UN goals in a more focused and collaborative way, although not all these groups have focused on Africa.

Examples of international design collaborations include the World Design Organization (WDO, 2019), the Oslo Manifesto (2016), and the International Union of Architects (2019). The World Design 
Organization identified seven sustainable development goals that were most relevant to industrial design and published them in a document for use by industrial designers (WDO, 2019). The Oslo Manifesto is a living document that reframes the goals to reflect how design contributes to the SDGs (see Appendix B). Hundreds of designers around the world have signed their support to the UN SDGs through this document. The International Union of Architects has produced a guide to illustrate how architecture overlaps with each of the goals (Mossin et al., 2018).

While it is helpful to understand what design organizations are doing, it is also important to understand what individual designers and researchers are doing to support these goals. A deeper and more transparent understanding of relevant research is vital to creating lasting connections and collaborations within the design community. Awareness of the topics being addressed, ongoing collaborations, and specific opportunities for improvement will enable the design community to address better the SDG-relevant issues that African countries are facing. More transparency will allow for the creation of a more aligned, connected, and global research community focused on sustainable development achieved through design.

This paper presents a first effort to review the design research literature pertaining to sustainable development in Africa. We seek to identify and describe the network of academic researchers working in this space. We describe existing patterns in research topics, characterize the nature of collaborations on these topics, and discuss opportunities for clarifying and aligning priorities to enable the design community to make progress towards realizing the SDGs.

\section{Methodology}

The goal of this paper is to identify research needs and opportunities for sustainable design in Africa as derived from the scientific literature. We accomplish this through a semi-systematic review of published literature that describes the activities of academic and other research groups (Snyder, 2019). A semi-systematic review was used because design related research was included from a variety of disciplines on the broad topic of sustainable development goals. The search for design literature on the African continent was primarily performed through Scopus. The search terms were broad and connected to UN SDG topics. This resulted in a broad collection of papers on a variety of topics all related to design for sustainable development in Africa. We identify patterns and incongruities in this research and suggest opportunities for alignment moving forward.

\subsection{Search terms}

Due to the broad scope of design and sustainable development in Africa, a variety of search terms were used to build a representative sample of topics. Some of the initial search terms used were design for development, design for developing countries, appropriate technology design, design for extreme affordability, and design for the base of the pyramid. Other search terms were then added that more closely reflected topics in the SDGs: sustainable agriculture, water, poverty, sustainable energy, healthcare, and sanitation. Relevant papers were included based on the inclusion criteria described below. References of the relevant papers and research that cite these papers were then screened for inclusion. The search terms were constrained to include only African-based research. This was done by using an "OR" list of African countries and the term "Africa" to capture research focused in broader regions such as Sub-Saharan, Western, Northern, or Eastern Africa.

\subsection{Inclusion criteria}

The primary inclusion criteria were that the literature be peer-reviewed and published in a scientific journal. Conference papers and books were excluded from this review. Papers were then included based on how relevant they were to both design and sustainable development in Africa. Articles were included only if the data studied was generated from Africa or if the research described a project implemented in Africa. Design-related research was included if the research involved the design of a product, service, or system at any stage in the design process. A broad inclusion for design was used to capture the work of researchers who are performing design related research but may not see themselves as design researchers. Design work included topics such as assessing the needs of 
stakeholders, evaluating solutions, or assessing current solutions to inform future designs. Lastly, sustainability and sustainable development are broad topics and inclusion was based on topics specifically covered in the UN SDGs. Examples of excluded papers are those describing the design of unimplemented policy ideas, architecture, life science projects and pharmaceuticals, law, business models, and construction projects.

\subsection{Analysis}

Nearly 300 papers were included in the analysis (see Appendix A). Information about these papers was compiled, coded, and evaluated to better understand the topics, locations, and collaborations represented in the literature. Primary topics of interest were coded using general terminology from different sectors and different groupings as reflected in the UN SDGs. Locations were determined based on the country of the primary author's stated affiliation. These primary locations were then grouped as "African" and "non-African." The African grouping refers to papers for which the primary author's affiliation was in Africa. "Non-African" refers to papers where the primary author's affiliation was located outside of Africa. Co-author location was also determined, using the same method as for the primary authors. An additional categorization was then made based on whether the primary author was university-affiliated ("University") or not ("Non-university").

\section{Results}

\subsection{Common topics}

Eighteen broad topics were identified. Of these, only six topics included more than seven papers. The three most frequently researched topics were energy, agriculture, and water. An evaluation of the three most common topics showed similarities between the research interests of African and non-African researchers, with water-related research as an exception $(-1)$. Only six papers on water-related research were African-based, whereas 51 papers on water-related research were based in non-African locations. Overall, the three most common topics for African-based researchers were energy, agriculture, and healthcare, compared to the three most common topics for non-African based researchers which were water, energy, and agriculture. These differences show a potential misalignment of research priorities between the two regions.

\section{Topics by Region}

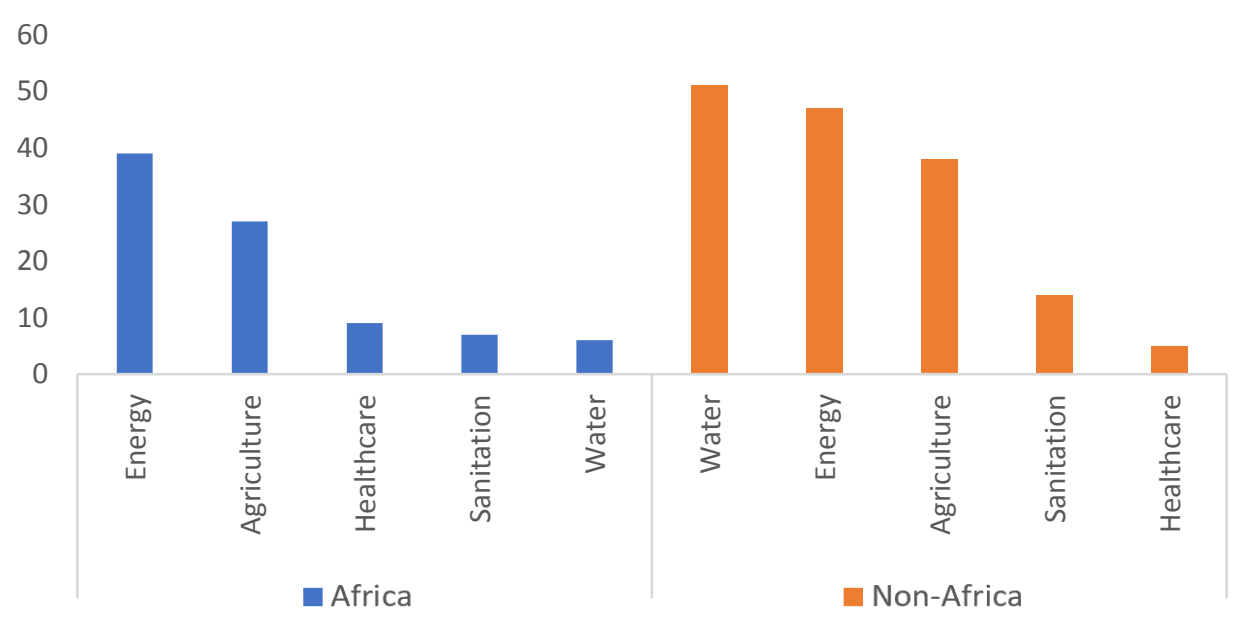

Figure 1. Research topics according to primary author's location

Primary research interests were also defined with respect to the researchers' location within Africa. Agriculture and energy had varying representation depending on the country in which the research 
was based (Figure 2). Kenya, Ghana, and Uganda had many papers on agriculture, for example, whereas South Africa and Ethiopia had primary focus on energy with relatively fewer papers on agriculture.

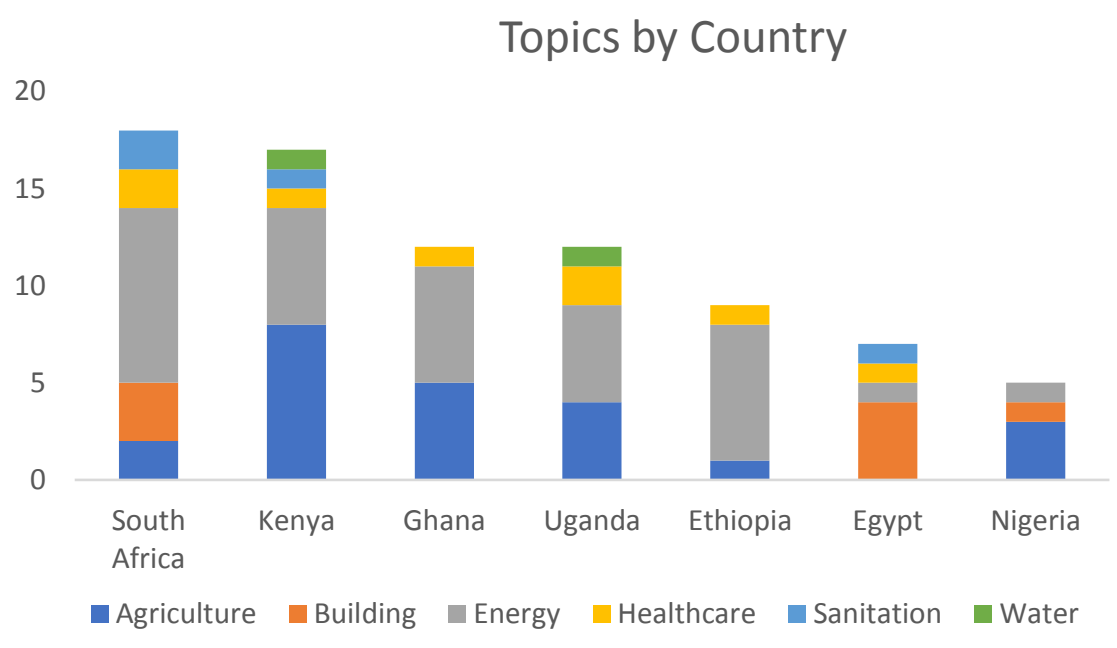

Figure 2. African based research from most common countries and split by research topics

\subsubsection{Energy}

Energy was the most represented research topic among all the included papers. Energy-related research was the primary topic of interest for African institutions and the second most common topic for non-African institutions. For African-generated research, energy was by far the most published topic with over a third of the papers reviewed being about energy. Because of energy's importance, a subtopic was assigned to each of the energy papers to further understand what specific areas were being researched.

Most energy-related papers examined biogas, home energy (such as cookstove or refrigeration), and microgrids (Figure 3). The papers were often focused on validating current designs or understanding user needs (e.g. Maré and Annegarn, 2017). Some fewer papers described new or novel products or services (e.g. Njenga et al., 2014). This evaluation also revealed differences in subtopics of interest between African and non-African researchers. Specifically, more non-African researchers produced work on home-related energy issues, whereas African researchers focused more on biogas.

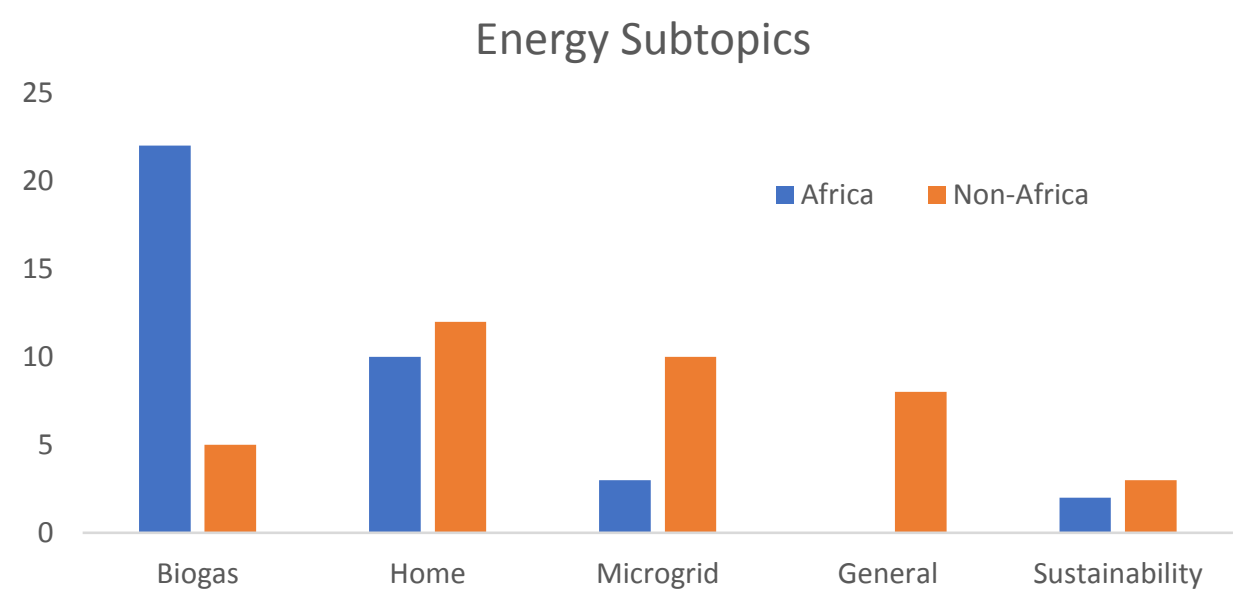

Figure 3. Five most common energy subtopics 


\subsubsection{Agriculture}

Agriculture was the second most common topic represented in the sampled literature. The main agriculture subtopics were post-harvest food loss and mechanization. A variety of other subtopics were also researched, but each of these subtopics included only one or two papers and were therefore not included in Figure 4. The post-harvest category was broad and included everything from pest detection after harvest (e.g. Njoroge et al., 2017) to post-processing with solar dryers (e.g. Rivier et al., 2018). No differences existed in the alignment of agriculture subtopics between African and non-African researchers.

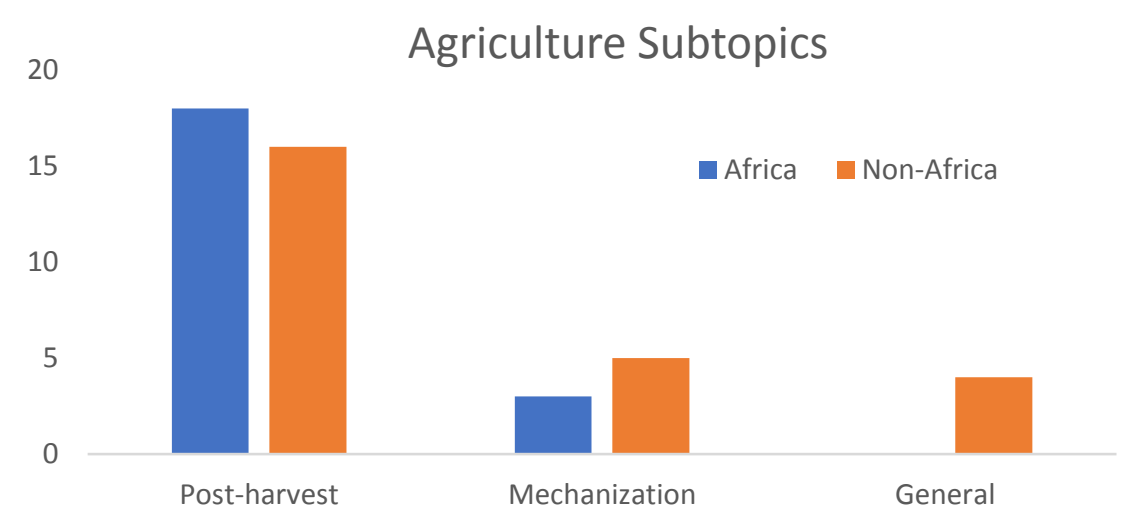

Figure 4. Three most common agriculture subtopics by primary author location

\subsubsection{Water}

Water-related research was driven largely by primary researchers outside of Africa. These papers looked at the design of water systems and water-related products such as handpumps. Most of the research related to handpumps described problems with maintenance service, which has been ineffective or nonexistent in the past decade (e.g. Foster et al., 2019). The lack of African-based, water-related research does not necessarily indicate a lack of importance to African researchers, but further exploration is important for understanding why this inconsistency exists.

\subsubsection{Sanitation}

Sanitation research focuses primarily on latrines. Availability and access to latrines is a major research topic, with most papers exploring user needs and implementation challenges (e.g. Goddard et al., 2018). Like the other sustainable development topics, sanitation and latrines are interconnected with many of the other development topics. This is seen in the connection between improved sanitation creating biogas and fertilizer outputs for more sustainable energy and agriculture (e.g. Odey et al., 2018).

\subsection{Collaboration network}

An analysis of co-authorship was conducted to understand the nature of research collaborations in this area. The coauthors' stated affiliations were mapped and classified with respect to geographic location of the paper's lead author. There were four categories to describe the co-author's location: "University in Africa", "Non-university in Africa", "University outside Africa", and "Non-university outside Africa". Co-authors from the same university or organization as the primary author were excluded. The network structure was then examined to find the number of papers that did not have African coauthors. As seen in Table 1, over half the papers did not have a co-author associated with an African organization.

Table 1. Percentage of papers with African and non-African coauthors

\begin{tabular}{|c|c|c|}
\hline $\begin{array}{l}\text { Primary Author } \\
\text { Location }\end{array}$ & $\begin{array}{l}\text { Percentage with African } \\
\text { Coauthor }\end{array}$ & $\begin{array}{l}\text { Percentage with non-African } \\
\text { Coauthor }\end{array}$ \\
\hline Africa & $46 \%$ & $33 \%$ \\
\hline Outside Africa & $42 \%$ & $51 \%$ \\
\hline
\end{tabular}


When looking at co-authors by research topic, a few differences are evident as seen in Figure 5. Of the four most researched topics, energy has the least co-authors per paper and agriculture has the most coauthors per paper. Within agriculture, African-based research has nearly twice as many African collaborations as non-African based papers. Also, the level of collaboration seen in energy and agriculture appears to be correlated to the level of alignment seen in the subtopics. Agriculture had high collaboration and strong subtopic alignment whereas energy had less collaboration and less alignment. This seems to support the idea that collaboration could be one reason for alignment or misalignment within a research topic.

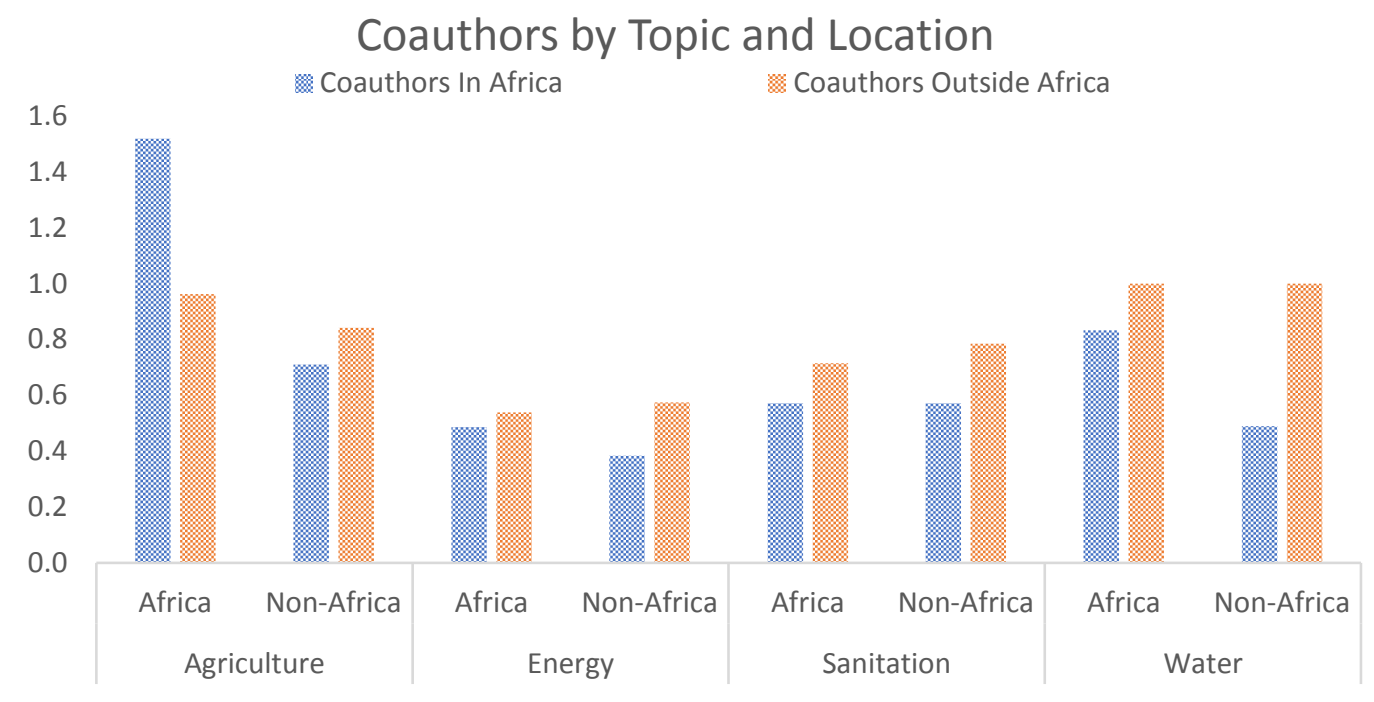

Figure 5. Average number of co-authors by topic and location

Co-author collaboration was also examined according to the primary author's affiliation: Non-university or University. While sanitation research from non-university affiliated researchers appeared to have the most collaborations, there was only one paper included in this statistic and was largely ignored. A trend did seem to appear that Non-university researchers had more collaborations on average per paper than University-affiliated researchers, with energy research as an exception.

\section{Coauthors by Topic and Affliation}

細 Coauthors In Africa Coauthors Outside Africa

4

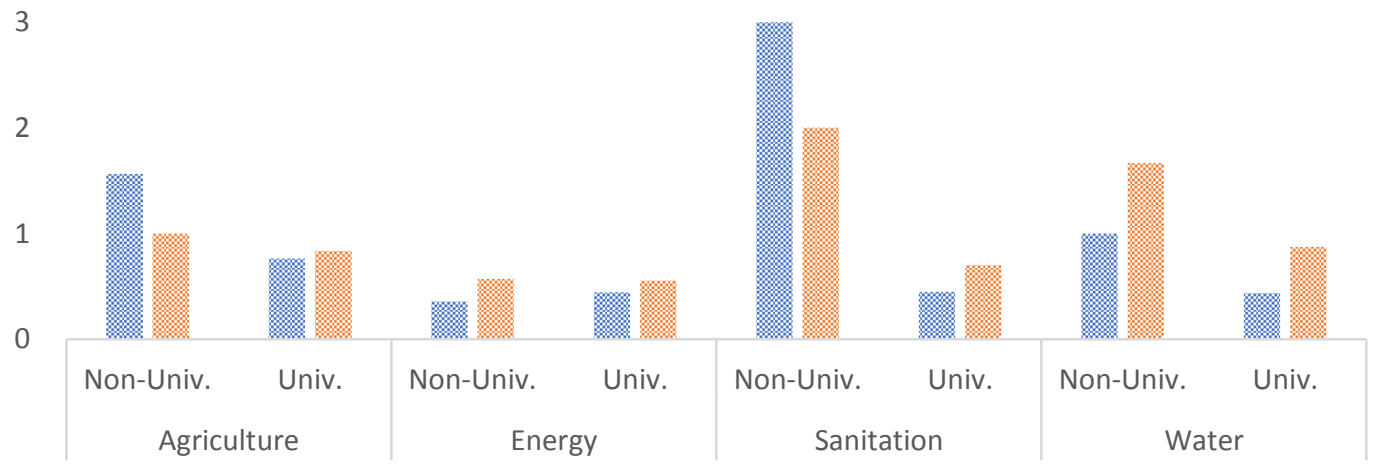

Figure 6. Average number of co-authors by topic and affiliation ( $n=1$ for Non-Univ. Sanitation) 
Collaborations defined by co-authors' associations or project associations were also examined at the country level. The map in Figure 7 was generated from the collaborations between the largest 11 countries, with six being African countries. It shows that most collaboration outside of Africa is focused in the US, Western and Central Europe, and Australia, with water being the most researched topic in the US, UK, and Australia. Agriculture is also an important topic for European collaborators.

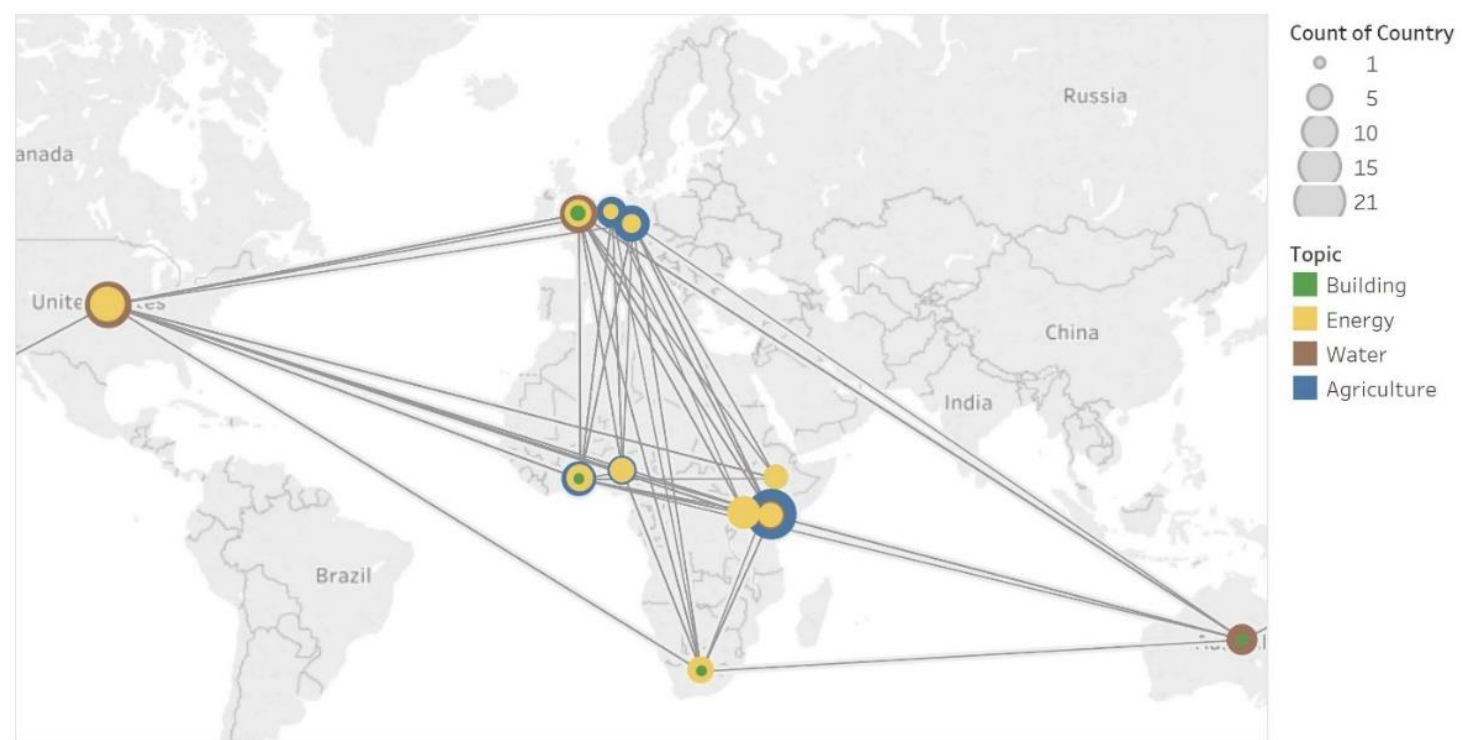

Figure 7. Map of author and Co-authors by main topics

\section{Discussion}

The main finding from this review is that representation of research topics and collaboration network structures differ between African and non-African-based research. These differences show a potential need for better alignment of research and improved collaboration between researchers.

The largest difference in representation of topics is seen in the high prevalence of water-related research from non-African based researchers, compared to the few water-related research papers that were produced from within Africa. This difference is likely multi-faceted but possible explanations may be funding differences between countries and regions or poor collaboration. Funding is often a driver for research topics by academics and needs to be investigated further to determine if there is a correlation between topics and funding in specific regions.

The largest difference in subtopic representation was within energy-related research. As seen in Figure 3, the difference between biogas for African-based research and home energy for non-African based research was the largest. This may also be due to funding differences and poor collaboration. It can be noted that the subtopic difference was not seen in agriculture and that agriculture had nearly twice as many co-authors per paper on average than energy-related topics. This correlation may show a link between collaboration and topic misalignment of African-based research versus non-African-based research.

The last major finding was seen in the number of co-authors from different groups and topics. Despite energy having the most papers, agriculture had double to triple as many co-authors per paper. Also, non-African based researchers had more co-authors outside of Africa than in Africa (42\% compared to $51 \%$ ). This was true across all categories (Figure 5). This preference to collaborate outside of Africa is also seen with African-based researchers in all categories except agriculture. While the difference in co-authorship in energy and agriculture might be due to the nature of the research, all the papers would likely benefit from more collaboration. It seems that increasing the percentage of papers with African co-authors should be a goal regardless of the research topic.

Moving forward, this review shows that aligning topics will be important for researchers working on design for sustainable development in Africa. This may come from better collaboration between researchers or alignment in funding. To better understand incentives, more work will need to be done on understanding funding in the design for sustainable development space. 


\subsection{Limitations}

This review has several limitations described below. Some of them were anticipated and addressed, and they are not included in this section. One example was a concern that groupings might have formed because of overrepresentation of certain authors. It was found that there were 261 unique primary researchers out of the 293 papers. This showed that a wide variety of papers were included, and author clustering was unlikely. Other limitations include the following:

- Peer review limitation likely excluded many practitioners.

- Some search terms (such as education) were not included and are likely underrepresented.

- Using co-authors to determine the level of collaboration is somewhat limited. This metric may describe mostly academic collaborations and may exclude other important collaborations such as with businesses, practitioners, government or implementation partners. This could be expanded in the future to include all partnerships in the papers and not just co-authors.

- The papers included were neither randomized or comprehensive and inclusion criteria were somewhat subjective. However, it is a starting point and an indication of what literature is being produced.

- The journals where African researchers publish may not have been included in Scopus where a majority of the research was conducted.

\subsection{Next steps}

Moving forward, a thorough understanding of more applied design work in African countries will be important. Because of the peer review restriction on the literature review, much of the work of the broader design community was likely left out. This can be seen by the lack of representation of commercialized products in the papers included. While the long-term success of the UN SDGs is likely dependent on new technologies and designs emerging from researchers, these solutions will also need to be applied. A better understanding of who is implementing sustainable design in Africa will help lead to partnerships and more impactful collaborations.

Additionally, findings from the literature review suggested a discrepancy between types of design problems selected for study by Africa-based researchers and non-Africa-based researchers. Better communication and collaboration between these researchers, as well as community and government participation in design research, will be necessary in the future to ensure that the most important topics are addressed in a viable way. Combining systems thinking and design thinking will be a useful framework for approaching these problems in the future. There is scarce research on the application of such 'systems design thinking' to sustainable development and the associated strategies. An opportunity exists to improve economic and social outcomes of development efforts in Africa by using systems design thinking to position local communities central to development activities.

\section{Conclusion}

The design community must play a significant role in achieving the UN SDGs. The purpose of this limited review was to provide a broad understanding of the extant scientific literature on design for sustainable development in Africa, and thus contribute to the design community's understanding of gaps and potential directions of new research. The selection of papers was meant to uncover the topics being addressed and the existing collaborations in the different research areas. The results show that energy, agriculture, and water are the most researched topics in the design for sustainable development in Africa with some differences existing in research priorities between African and non-African researchers. This difference shows misalignment between water research in the two regions and requires further exploration to understand why this difference exists. The analysis also showed that about half of the papers had a co-author affiliated to an African institution. This collaboration was not equal across the topics and may be better in certain research communities than others.

Further understanding of the important players beyond scientific researchers engaged in design through commercial products, services, or systems is an important next step. Bridging and connecting 
all change agents towards actual practice are necessary for realizing the vision of the UN Sustainable Development Goals by 2030.

\section{Acknowledgements}

Partial support of this work by the Donald C. Graham Endowed Chair and the Undergraduate Research Opportunities Program at the University of Michigan is gratefully acknowledged.

\section{References}

Achieving the Sustainable Development Goals by Design [WWW Document] (2019), World Des, Organ. URL https://wdo.org/about/vision-mission/un-sdgs/ (accessed 4.8.19).

Design Society (2019), Africa-Design Initiative [WWW Document], Des. Soc. URL https://www.designsociety. org/group/39/AFRICA-DESIGN (accessed 11.11.19).

Djeflat, A. (2017), "Design and Engineering Capacity Building for a Sustainable Development of African Economies: The Case of Algeria", In: Ahmed, A. (Ed.), Managing Knowledge and Innovation for Business Sustainability in Africa, Palgrave Studies of Sustainable Business in Africa, Springer International Publishing, Cham, pp. 137-151. https://doi.org/10.1007/978-3-319-41090-6_8

Foster, T., McSorley, B. and Willetts, J. (2019), "Comparative performance evaluation of handpump watersupply technologies in northern Kenya and The Gambia", Hydrogeol. J, Vol. 27, pp. 535-551. https://doi.org/10.1007/s10040-018-1865-4

Goddard, F.G.B. et al. (2018), "Quantifying user preferences for sanitation construction and use: Application of discrete choice experiments in Amhara, Ethiopia", Trop. Med. Int. Health, Vol. 23, pp. 1364-1373. https://doi.org/10.1111/tmi.13163

Maré, M. and Annegarn, H.J. (2017), "The Use of Willingness to Pay in Determining Customer Preferences for Improved Flame-Based Cookstove Features in Two South African Study Areas", Soc. Mark. Q, Vol. 23, pp. 335-353. https://doi.org/10.1177/1524500417732773

Mossin, N. et al. (2018), An Architecture Guide to the UN 17 Sustainable Development Goals.

Njenga, M. et al. (2014), "Additional cooking fuel supply and reduced global warming potential from recycling charcoal dust into charcoal briquette in Kenya", J. Clean. Prod, Vol. 81, pp. 81-88. https://doi.org/ 10.1016/j.jclepro.2014.06.002

Njoroge, A.W. et al. (2017), "Bioacoustics of Acanthoscelides obtectus (Coleoptera: Chrysomelidae: Bruchinae) on Phaseolus vulgaris (Fabaceae)", Fla. Entomol, Vol. 100, pp. 109-115. https://doi.org/10.1653/024.100.0116

Odey, E.A. et al. (2018), "Sanitation approach toward resource recovery in rural and semi-urban centers: Insight from South South Nigeria", Environ. Qual. Manag, Vol. 28, pp. 13-19. https://doi.org/10.1002/tqem.21583

Oslo Manifesto [WWW Document] (2016), Oslo Manif, URL http://oslomanifesto.org/ (accessed 4.15.19).

Patra, S.K. and Muchie, M. (2017), "Engineering research profile of countries in the African Union", Afr. J. Sci. Technol. Innov. Dev, Vol. 9, pp. 449-465. https://doi.org/10.1080/20421338.2017.1341732

Rivier, M. et al. (2018), "Modeling a process combining a cereal dryer with a bioenergy unit for equipment design in developing countries", J. Food Process Eng, Vol. 41, pp. e12836. https://doi.org/10.1111/jfpe.12836

Snyder, H. (2019), "Literature review as a research methodology: An overview and guidelines", J. Bus. Res, Vol. 104, pp. 333-339. https://doi.org/10.1016/j.jbusres.2019.07.039

United Nations (2019), The Sustainable Development Goals Report 2019, UN, New York. 


\section{Appendix A - Research papers data}

The collected papers were compiled into an MS Excel spreadsheet from which most of the statistics were generated. The information on the papers was collected from Scopus. Each row is a single paper with the columns being attributes. These attributes were sometimes in aggregate form from Scopus and were split into other single columns such as the Authors1, Authors2, etc. The abstracts of all the papers was also included for reference and for help. A link is provided here to a Google Sheet version of the data.

https://docs.google.com/spreadsheets/d/12ul7t16FURUQBhcDWkKXmJURIPBNTKoTeX6pkZ3DJa M/edit?usp=sharing

\section{Appendix B - Oslo Manifesto}

The Oslo Manifesto mentioned in the paper is living document hosted on www.oslomanifesto.org. Because the actual signatures were difficult to search through in their online version, a table was made as of April 2019 with the names that were present. These were compiled for further research and for understanding. A version of this table can be found in the link below.

https://docs.google.com/spreadsheets/d/1Tp-EqFm5ZOcGfazro7ZYI62r6blKD1eeqk9-

RD1QXn0/edit?usp=sharing 